\title{
Event-Level Association Between Daily Alcohol Use and Same-Day Nonadherence to Antiretroviral Therapy Among Young Men Who Have Sex With Men and Trans Women Living With HIV: Intensive Longitudinal Study
}

Caitlin Marie Turner ${ }^{1,2}$, MPH; Dillon Trujillo ${ }^{1}$, MPH; Victory Le ${ }^{1,3}$, MA; Erin C Wilson ${ }^{1,4}$, MPH, DrPH; Sean Arayasirikul ${ }^{1,5}, \mathrm{PhD}$

\footnotetext{
${ }_{1}$ Trans Research Unit for Equity, Center for Public Health Research, San Francisco Department of Public Health, San Francisco, CA, United States

${ }^{2}$ Doctoral Program in Epidemiology \& Translational Science, Department of Epidemiology and Biostatistics, University of California, San Francisco, CA, United States

${ }^{3}$ California School of Professional Psychology, Alliant International University, San Francisco, CA, United States

${ }^{4}$ Department of Epidemiology and Biostatistics, University of California, San Francisco, CA, United States

${ }^{5}$ Department of Pediatrics, School of Medicine, University of California, San Francisco, CA, United States
}

\section{Corresponding Author:}

Caitlin Marie Turner, MPH

Trans Research Unit for Equity

Center for Public Health Research

San Francisco Department of Public Health

25 Van Ness, Ste 500

San Francisco, CA, 94102

United States

Phone: 14155549018

Email: caitlin.turner@sfdph.org

\section{Abstract}

Background: Young trans women (TW) and men who have sex with men (MSM) are disproportionately impacted by HIV. Optimizing adherence to antiretroviral therapy (ART) is one mechanism by which public health experts aim to achieve favorable HIV health outcomes while reducing disease transmission. However, alcohol use is prevalent among young TW and MSM and threatens optimal adherence. In addition, the daily variations in alcohol use and ART adherence and their association with each other are poorly understood, warranting more appropriate methodological approaches, such as analysis of ecological momentary assessment (EMA) data.

Objective: The aim of this analysis is to characterize the association between daily alcohol use and same-day ART nonadherence captured by an EMA study of young MSM and TW living with HIV in San Francisco.

Methods: Young MSM and TW enrolled in the Health eNav digital HIV care navigation intervention were included in the analytic sample ( $\mathrm{N}=113)$. Data on alcohol and ART use were collected by daily EMA surveys administered via text messaging and were analyzed over 30 days of follow-up. A multivariable mixed-effects logistic regression model adjusting for baseline sociodemographic characteristics was specified to investigate whether daily alcohol use was associated with same-day ART nonuse.

Results: Daily alcohol use was associated with higher same-day ART nonuse. On average, participants drank alcohol on 15.20 (SD 8.93) days and used ART on 15.19 (SD 10.16) days out of 30 days. Daily alcohol use was associated with 1.89 (95\% CI 1.14-3.15) times the adjusted odds of same-day ART nonuse for each participant.

Conclusions: Results are consistent with other analyses of daily alcohol and ART use and underscore the importance of individually targeted interventions that are sensitive to each participant's dynamic risk environment.

International Registered Report Identifier (IRRID): RR2-10.2196/16406

(JMIR Mhealth Uhealth 2020;8(10):e22733) doi: 10.2196/22733 


\section{KEYWORDS}

ecological momentary assessment; event-level; alcohol; antiretroviral therapy; men who have sex with men; trans women; adherence

\section{Introduction}

Men who have sex with men (MSM) and trans women (TW) are disproportionately affected by HIV. MSM made up $70 \%$ of new HIV diagnoses in the United States in 2017 [1]. Approximately $21.7 \%$ of TW in the United States live with HIV and are over 30 times more likely to live with HIV compared to the rest of the US adult population [2].

The Joint United Nations Programme on HIV/AIDS (UNAIDS) developed 90-90-90 targets for 2020 to increase HIV care outcomes among all people living with HIV [3]. The last target - antiretroviral therapy (ART) uptake and adherence-is essential for viral suppression. Nonadherence to ART negatively impacts HIV progression [4,5] and is a substantial barrier to achieving favorable HIV health outcomes. Optimal ART adherence is achieved by only $63.4 \%$ of adults living with HIV $[6,7]$.

With HIV-related stigma and other systems of oppression that target sexual and gender minority people, ART adherence is even poorer among MSM and TW. According to a 2018 HIV surveillance report by the Centers for Disease Control and Prevention (CDC), only $58 \%$ of gay and bisexual men living with HIV were virally suppressed [8]. In 2017, only $64.3 \%$ of TW in San Francisco had an undetectable viral load [9]. Low viral suppression among MSM and TW underscores the barriers to ART uptake and adherence for these populations.

Researchers have identified a number of intervention targets for improving ART adherence [5], including alcohol use [10,11]. Some mechanistic pathways involving alcohol use and ART adherence have been proposed. It is theorized that alcohol use impairs immunological functioning and viral suppression, and that this pathway is mediated by ART nonadherence [12,13]. Alcohol use could also impair cognitive functioning and subsequently interfere with the ability to adhere to HIV medications [14]. Alcohol use is prevalent among those living with HIV [15-18] and among MSM and TW [19-22], as it is hypothesized to be a coping strategy for psychological distress associated with HIV-related stigma [23] and discrimination based on sexual [24] or gender identity [25].

Alcohol use was associated with ART nonadherence in previous studies $[10,11,26]$; however, such studies are lacking among individuals living with HIV who have marginalized sexual and gender identities. Moreover, most studies of the effects of alcohol use on ART adherence are retrospective or gather data infrequently [27], failing to capture the temporality between alcohol and ART use and the day-to-day fluctuations inherent in both of these behaviors.

Ecological momentary assessment (EMA) data have the potential to characterize day-to-day or more frequent variations in health behaviors. EMA is a real-time data collection technique administered via technological platforms, such as handheld devices or mobile phones. A number of previous studies have used EMAs to capture fine-grained variations in substance use [28-31] and, more recently, behaviors among people living with HIV [28,32-34]. A number of studies have shown that EMA is feasible and acceptable among MSM [34-37] and persons who use substances [28,29]; one study showed moderate compliance to EMA among young MSM and TW living with HIV [38].

To our knowledge, 2 EMA studies were conducted to evaluate the relationship between alcohol use and ART adherence $[39,40]$. Parsons and colleagues [39] found that alcohol use was associated with 9 times the odds of HIV medication nonadherence among 272 HIV-positive men and women over 14 days of follow-up. Barai and colleagues [40] discovered that alcohol use was associated with lower odds of viral medication adherence and viral suppression among 234 women living with HIV. However, no studies have examined the alcohol use and ART nonadherence association in young MSM and TW living with HIV.

Given these research gaps, this study utilizes data from a relatively large sample of MSM and TW who participated in EMA as part of a larger HIV digital care navigation intervention. Using this data, we specify an intensive longitudinal model that assesses whether event-level alcohol use is associated with same-day ART nonadherence among young MSM and TW living with HIV in San Francisco.

\section{Methods}

Data for this analysis come from the study of Health eNav, a Digital HIV care navigation intervention conducted at the San Francisco Department of Public Health from 2017 to 2018. Study procedures were approved by the University of California, San Francisco (IRB \#16-19675). Health eNav is a digital HIV care navigation intervention that employs SMS text messaging to improve HIV care continuum outcomes for young MSM and TW living with HIV in San Francisco.

\section{Participants}

Eligibility criteria were defined as follows: (1) self-identifying as MSM or TW; (2) aged 18-34 years; (3) living in San Francisco; and (4) newly diagnosed with HIV, not engaged/retained in care, or not virally suppressed. Specifically, we defined new HIV diagnoses as those that occurred within the last 12 months of enrollment in the study. If potential participants missed more than 2 HIV care appointments in the last year, they were considered as not engaged or retained in care. Potential participants who had a detectable viral load were considered as not virally suppressed. Potential participants were recruited via convenience sampling from 5 clinics and community-based organizations serving young people living with HIV in San Francisco. Study recruitment was advertised with posters, palm cards, and presentations; staff referred potential participants to the study through phone, email, or in-person meetings. The enrolled participants were also invited to refer peers from within their social networks. 
An in-person or telephone eligibility screening was administered to recruits. Eligible participants then met with research staff situated at the local health department to obtain informed consent and enroll into the study. Overall, 171 people were screened. Out of those, 140 were eligible, and 120 participants enrolled in the study. Out of these 120 participants, 113 (94.2\%) participants engaged in the EMA component of the study and comprised the analytical sample of this paper.

\section{Data Collection, Measures, and Variable Selection}

Procedures for the Health eNav study are described in depth in a prior protocol [41]. Briefly, Health eNav was a 6-month digital HIV care navigation intervention among young MSM and TW living with HIV, a disproportionate number of whom experienced gaps in HIV care and subsequent disparities in ART use and viral suppression. All Health eNav participants were connected to a digital HIV care navigator who facilitated linkage to, engagement in, and retention in HIV care via 2-way SMS text messaging. This study analyzes data collected from the following sources:

1. Daily EMA text surveys delivered during the first 90 days of the larger intervention, focused on capturing daily substance use, affect, sexual behaviors, and ART use in the 24 hours prior to receiving each survey.

2. Computer-administered self-interviewing (CASI) surveys at baseline, 6-, 12-, and 18-month follow-up that gathered information on participants' sociodemographic characteristics and HIV-related care outcomes.

We assessed the possible association between daily alcohol use and same-day ART adherence (measured by the EMA surveys) after adjusting for covariates (measured by baseline CASIs). We restricted our analysis to the first 30 days of EMA participation to be consistent with other EMA studies. Moreover, we observed that restricting to 30 days allowed us to maximize the nuance with which we characterized alcohol use and ART while minimizing any missingness due to participant fatigue.

Participants received automated SMS text message surveys once per day at the time of their choice (from among $8 \mathrm{AM}$, noon, or $8 \mathrm{PM}$ ) for the first 90 days of the intervention. The text survey was delivered through mSurvey [42]. Participants were required to complete EMA surveys within 24 hours, or the survey would time out. Each EMA survey comprised anywhere from 17 to 31 daily EMA texts depending on the responses. For example, if a participant reported on the EMA survey that they had sex within the last 24 hours, they would then receive follow-up questions about whether condoms were used and whether certain substances were used during sex. Had they not reported having sex, they would not receive questions about condom use or concurrent substance use. EMA surveys took 5 minutes or less to complete each day.

Participants were compensated US \$1 for each completed EMA survey for up to US $\$ 90$ over the EMA portion of the study. If participants completed more than $80 \%$ of their EMA surveys, they earned a bonus of US $\$ 100$. Incentives were provided in the form of a gift card.

Data on alcohol use and ART adherence were collected daily for 30 days, and participants were inquired about their alcohol and ART use within the 24 hours prior to each EMA. We dichotomized daily alcohol use as "any use" versus "no use." For ease with interpretation (since we hypothesized that alcohol use would be associated with nonuse of ART), we operationalized the outcome as daily ART nonuse compared to ART use (reference group). ART use was gathered from a question on the EMA survey that asked, "In the past 24 hours, did you take your ART meds?"

Factors that we hypothesized would confound the relationship between alcohol and ART use were selected a priori based on the creation of a directed acyclic graph. Age (in years); race/ethnicity (Black/African American, Hispanic/Latinx, other/multiple, or White); and education level (less than high school, high school or General Educational Development [GED], and at least some college) were included for adjustment in the main analytic model. We also included housing status (living with a family member, friend, or partner who rents/owns a home; living in temporary/transitional housing; experiencing homelessness; or renting/owning a home), recent incarceration, and competing needs (eg, foregoing HIV medications to afford basic needs such as food, housing, or clothing, and vice versa) as baseline covariates. We hypothesized that young TW and MSM who were recently diagnosed with HIV might experience heightened alcohol use and barriers to ART due to newly experienced stigma and identity development related to seroconversion. Therefore, we included HIV diagnosis timing (within the last 12 months of the baseline survey versus more than 12 months before baseline) as a covariate. Finally, we included number of substances (excluding alcohol or tobacco and including any combination of marijuana, heroin, methamphetamine, amphetamines, hallucinogens, crack/cocaine, heroin, opiates, or poppers) used at baseline, defined as 0,1 , or more than 1 .

\section{Statistical Analysis}

All analyses were conducted using Stata 14 software (StataCorp). Baseline sociodemographic characteristics, HIV diagnosis timing, and substance use, as gathered by the CASIs, were described for the entire sample. Alcohol use and ART nonuse were characterized over the 30-day period using EMA data. The main analysis, testing the association between daily alcohol use and same-day ART nonuse, comprised a mixed-effects regression model with a random intercept for each participant, adjusting for the aforementioned covariates.

\section{Results}

Table 1 shows the demographic breakdown of participants in the analytic sample. The average age was about 28 years. Participants were racially/ethnically diverse, with most identifying as Black/African American, Hispanic/Latinx, or "Other"/multiple races, and about a quarter of the sample identifying as White. Though most participants had some college education or more $(66 / 113,58.4 \%)$, only a third of the sample rented or owned their living space. More than a quarter of the sample experienced competing needs (foregoing HIV medications to afford basic needs and vice versa). About a third of participants had been recently diagnosed with HIV, and the 
majority of participants reported using more than 2 substances (other than alcohol and tobacco) in the last 6 months.

Out of the 3390 total EMA surveys sent, 2022 (59.7\%) were completed across Health eNav participants over the 30-day follow-up period. The median number of surveys completed, out of a total of 30 possible surveys, was 20 (IQR 8-27). There was a 97.85\% overlap in missing values for ART and alcohol use; that is, most participants who did not respond to whether or not they used ART on a given day also did not respond to whether or not they used alcohol on that day. Alcohol use was reported on $19.1 \%$ of completed EMA surveys (386/2022); ART nonadherence was reported on $15.8 \%$ (320/2022) of completed EMA surveys.

Table 1. Baseline sociodemographic characteristics, HIV diagnosis timing, and substance use among young men who have sex with men and trans women living with HIV who participated in ecological momentary assessment text surveys over 30 days of follow-up, Health eNav (N=113), San Francisco, 2017-2019.

\begin{tabular}{ll}
\hline Sociodemographic characteristics & Values $^{\mathrm{a}}$ \\
\hline Age (years), mean (SD) & $27.7(3.96)$ \\
Race/ethnicity, $\mathbf{n}(\boldsymbol{\%})$ & $22(19.47)$ \\
$\quad$ Black, non-Hispanic/Latinx & $37(32.74)$ \\
$\quad$ Hispanic/Latinx & $26(23.01)$ \\
Other or multiple races, non-Hispanic/Latinx & $28(24.78)$ \\
White, non-Hispanic/Latinx & \\
Education level, $\mathbf{n}(\%)$ & $11(9.73)$ \\
Bachelor's or higher & $55(48.67)$ \\
Some college or Associate's degree & $36(31.86)$ \\
High school/GED & $11(9.73)$ \\
Less than high school &
\end{tabular}

Current living situation, $n(\%)$

Rent/own

Lives with a friend, partner, or family member

Temporary or transitional housing

$41(36.28)$

Homeless/shelter

Went without HIV medications to afford basic needs, last 6 months, n (\%)

No

Yes

Went without basic needs to afford HIV medications, last 6 months, n (\%)

No

Yes

Incarcerated, last 6 months, $n(\%)$

No

Yes

HIV diagnosis timing (when diagnosed with HIV), n (\%)

Diagnosed more than 12 months prior to baseline

Diagnosed within 12 months prior to baseline survey

Substance use (number of substances used [other than alcohol and tobacco]) in last 6 months, $n$ (\%)

0

1

2 or more

$67(59.29)$

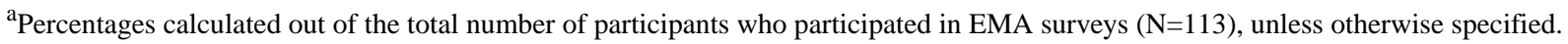
${ }^{\mathrm{b}} \mathrm{GED}$ : General Educational Development. 
Analysis of EMA data revealed that, on average, participants drank alcohol on 15.20 (SD 8.93) days and used ART on 15.19 (SD 10.16) days out of 30 days. Event-level alcohol use was associated with 1.89 (95\% CI 1.14-3.15) times the adjusted odds of same-day ART nonuse for each participant (Table 2). 
Table 2. Mixed-effects model assessing daily alcohol use and same-day ART nonadherence among young MSM and TW living with HIV who participated in EMA text surveys over 30 days of follow-up, Health eNav (N=113), San Francisco, 2017-2019.

\begin{tabular}{|c|c|c|}
\hline \multirow[t]{2}{*}{ Variables } & \multicolumn{2}{|c|}{ Mixed-effects logistic regression } \\
\hline & $\mathrm{AOR}^{\mathrm{a}}(95 \% \mathrm{CI})$ & $P$ value \\
\hline \multicolumn{3}{|l|}{ Exposure (used alcohol in the last 24 hours) } \\
\hline No & $\operatorname{Ref}^{b}$ & $\mathrm{~N} / \mathrm{A}^{\mathrm{c}}$ \\
\hline Yes & $1.89(1.14-3.15)$ & .01 \\
\hline Age & $1.04(0.92-1.19)$ & .52 \\
\hline \multicolumn{3}{|l|}{ Race/ethnicity } \\
\hline White, non-Hispanic/Latinx & Ref & N/A \\
\hline Black, non-Hispanic/Latinx & $3.97(0.91-17.41)$ & .07 \\
\hline Hispanic/Latinx & $0.94(0.28-3.20)$ & .92 \\
\hline Other or multiple races, non-Hispanic/Latinx & $0.27(0.07-1.09)$ & .07 \\
\hline \multicolumn{3}{|l|}{ Education level } \\
\hline Bachelor's or higher & Ref & N/A \\
\hline Some college or Associate's degree & $1.77(0.35-9.10)$ & .49 \\
\hline High school/GED ${ }^{d}$ & $8.96(1.54-52.15)$ & .02 \\
\hline Less than high school & $2.25(0.21-23.80)$ & .50 \\
\hline \multicolumn{3}{|l|}{ Current living situation } \\
\hline Rent/own & Ref & N/A \\
\hline Lives with a friend, partner, or family member & $0.34(0.08-1.44)$ & .14 \\
\hline Temporary or transitional housing & $0.33(0.10-1.11)$ & .07 \\
\hline Homeless/shelter & $0.73(0.16-3.37)$ & .68 \\
\hline \multicolumn{3}{|c|}{ Went without HIV medications to afford basic needs, last 6 months } \\
\hline No & Ref & N/A \\
\hline Yes & $3.67(1.06-12.71)$ & .04 \\
\hline \multicolumn{3}{|c|}{ Went without basic needs to afford HIV medications, last 6 months } \\
\hline No & Ref & N/A \\
\hline Yes & $0.26(0.07-1.04)$ & .06 \\
\hline \multicolumn{3}{|l|}{ Incarcerated, last 6 months } \\
\hline No & Ref & N/A \\
\hline Yes & $0.77(0.19-3.14)$ & .71 \\
\hline \multicolumn{3}{|l|}{ HIV diagnosis timing (when diagnosed with HIV) } \\
\hline Diagnosed more than 12 months prior to baseline & Ref & N/A \\
\hline Diagnosed within 12 months prior to baseline survey & $0.28(0.09-0.89)$ & .03 \\
\hline \multicolumn{3}{|c|}{ Substance use (number of substances used [other than alcohol and tobacco]) in last 6 months } \\
\hline 0 & Ref & N/A \\
\hline 1 & $0.55(0.12-2.51)$ & .44 \\
\hline 2 or more & $1.38(0.40-4.71)$ & .61 \\
\hline
\end{tabular}

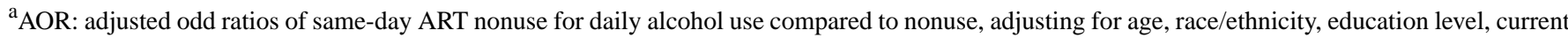
living situation, competing needs, incarceration, HIV diagnosis timing, and substance use.

${ }^{\mathrm{b}}$ Ref: reference.

${ }^{\mathrm{c}} \mathrm{N} / \mathrm{A}$ : not applicable.

${ }^{\mathrm{d}} \mathrm{GED}$ : General Educational Development. 


\section{Discussion}

In summary, daily alcohol use was associated with higher same-day ART nonuse. Findings from this analysis corroborate other studies of the association between alcohol use and ART nonadherence, many of which collected data cross-sectionally or retrospectively. A meta-analysis of studies examining this association showed that the combined odds of ART adherence were lower among study participants who used alcohol. However, the authors noted that effect estimation would be improved with prospective, event-level examinations of alcohol and ART use and by assessing this association for different sociodemographic subgroups [43]. This analysis uses prospective, event-level data and examines this association for young MSM and TW living with HIV, 2 populations disproportionately affected by HIV. Showing a longitudinal association provides stronger evidence that interventions targeting alcohol use may also improve ART adherence, which is an important step in achieving optimal HIV care outcomes [3].

Findings from this study should be interpreted with a number of limitations in mind. First, intermittent missingness and dropout are issues inherent with EMA data collection due to increased burden on participants [44], and these issues were present in our sample. Full or partial multiple imputations have been recommended as the best approach for improving precision of estimates where missingness is an issue [44]. However, practical applications of these methods, especially with respect to longitudinal modeling, have produced mixed results. One study found that multiple imputations produced similar or even increased standard errors [45] compared with complete case data. With these observations in mind, we chose to analyze complete case data. Thus, our results are only generalizable to the participants for whom we had complete data.

Second, data were collected via self-report, and participants may have underreported their alcohol use and ART nonadherence behaviors. This could have potentially washed out the estimated effect. However, the results we observed still showed statistical significance. A third limitation was misclassification of exposure. Dichotomizing alcohol use as "any versus none" effectively grouped together participants who drank casually with those who drank heavily. However, such dichotomizing was necessary to preserve precision of estimates. In addition, we suspected that this misclassification was nondifferential and independent, which would bias results toward the null. If anything, the effect estimate we observed underestimated the true, underlying association. A fourth limitation was the small size of the sample, precluding stratified analyses by key demographics within which the alcohol-ART association may have varied. However, given the daily administration of EMA surveys, we are confident that the effect estimate provided was statistically precise for the entire sample. A fifth limitation was that we restricted the follow-up window of EMA surveys to 30 days. However, this analytic decision was informed by prior EMA studies conducted over 30-day-or-shorter time windows. Since EMA data collection was embedded within the larger digital care navigation intervention, losses-to-follow-up attributable to participation within the larger intervention may have impacted engagement in EMA outside of the 30-day window. Moreover, expanding the EMA follow-up window beyond 30 days could have produced an effect estimate that was less representative of the entire sample since participant fatigue and subsequent nonresponses were more of an issue beyond the first 30 days. Finally, results were not generalizable outside of young MSM and TW living in San Francisco.

The limitations of this analysis pave the way for future research. Given the dearth of research on moderation of the alcohol-ART association by key sociodemographic characteristics such as gender and race [43], future studies should utilize EMA methods in other key subgroups. TW living with HIV, many of whom experience pervasive gaps in HIV care and clinical outcomes, represented only a small percentage of the participants in this study, precluding statistically precise estimations of the effect of alcohol use on ART nonadherence for this subgroup. Future research should be conducted on larger samples of TW to explore how the alcohol-ART association varies by gender. Since this analysis was underpowered to assess interactions between alcohol use, substance use, and mental health, future studies with larger sample sizes could centralize comorbidities between those factors. In addition to focusing on individual behaviors, these future studies could examine the multilevel interplay between alcohol use and structural factors like racism, housing instability, or competing needs and their impact on ART adherence. Alcohol use is one of many modifiable factors that could affect adherence to HIV medications.

Finally, future EMA studies would benefit from a thorough consideration of institutional and individual barriers to EMA survey completion in order to reduce missing responses. A previous analysis of Health eNav EMA data confirmed that housing instability, incarceration, competing needs, and educational constraints interfered with EMA completion for young MSM and TW, even though participants had continuous access to cellular devices [38]. While one recommendation to preemptively address participant nonresponse would be to invest in procedures that sustain retention over the follow-up period, structural barriers to such an investment (eg, systemic marginalization of the populations served or lack of grant funding) highlight the unrealistic nature of such a recommendation. Dismantling systemic oppression would best improve study retention and even remove the need to have studies on health inequities in the first place. Until then, studies such as this one highlight the need to apply tailored approaches to implementation of digital interventions within under- and misrepresented populations.

To our knowledge, this is the first intensive longitudinal analysis of alcohol and ART use among young MSM and TW living with HIV. This analysis highlights important considerations in examining daily ART use among populations especially vulnerable to substance use and medication nonadherence. 


\section{Acknowledgments}

The authors would like to acknowledge the Health eNav study staff and participants. In addition, we would like to thank Mi-Ok Kim, PhD, and David Glidden, PhD, at the University of California, San Francisco, for their guidance in conceptualizing the analytic method employed in this paper. This work was supported by the Health Resources and Services Administration (award number H97HA28895).

\section{Conflicts of Interest}

None declared.

\section{References}

1. Centers for Disease Control and Prevention. HIV Surveillance Report, 2017; volume 29. URL: http://www.cdc.gov/hiv/ library/reports/hiv-surveillance.html [accessed 2020-06-01]

2. Baral SD, Poteat T, Strömdahl S, Wirtz AL, Guadamuz TE, Beyrer C. Worldwide burden of HIV in transgender women: a systematic review and meta-analysis. Lancet Infect Dis 2013 Mar;13(3):214-222. [doi: 10.1016/S1473-3099(12)70315-8] [Medline: 23260128]

3. 90-90-90: An ambitious treatment target to help end the AIDS epidemic. Joint United Nations Programme on HIV/AIDS. 2014. URL: http://www.unaids.org/sites/default/files/media asset/90-90-90 en.pdf [accessed 2020-06-01]

4. Bangsberg DR, Perry S, Charlebois ED, Clark RA, Roberston M, Zolopa AR, et al. Non-adherence to highly active antiretroviral therapy predicts progression to AIDS. AIDS 2001 Jun 15;15(9):1181-1183. [doi:

10.1097/00002030-200106150-00015] [Medline: 11416722]

5. Simoni JM, Amico KR, Pearson CR, Malow R. Strategies for promoting adherence to antiretroviral therapy: a review of the literature. Curr Infect Dis Rep 2008 Nov;10(6):515-521 [FREE Full text] [doi: 10.1007/s11908-008-0083-y] [Medline: 18945394]

6. Centers for Disease Control and Prevention. Monitoring selected national HIV prevention and care objectives by using HIV surveillance data-United States and 6 dependent areas, 2017. HIV Surveillance Supplemental Report, Volume 24, Number 3. 2019 Jun. URL: https://www.cdc.gov/hiv/pdf/library/reports/surveillance/ cdc-hiv-surveillance-supplemental-report-vol-24-3.pdf [accessed 2020-10-01]

7. Bezabhe WM, Chalmers L, Bereznicki LR, Peterson GM. Adherence to Antiretroviral Therapy and Virologic Failure: A Meta-Analysis. Medicine (Baltimore) 2016 Apr;95(15):e3361 [FREE Full text] [doi: 10.1097/MD.00000000000003361] [Medline: 27082595$]$

8. Selected National HIV Prevention and Care Outcomes. Centers for Disease Control and Prevention. 2018. URL: https:/ /www.cdc.gov/hiv/pdf/library/slidesets/cdc-hiv-prevention-and-care-outcomes-2018.pdf [accessed 2019-06-01]

9. Baguso GN, Turner CM, Santos G, Raymond HF, Dawson-Rose C, Lin J, et al. Successes and final challenges along the HIV care continuum with transwomen in San Francisco. J Int AIDS Soc 2019 Apr;22(4):e25270 [FREE Full text] [doi: 10.1002/jia2.25270] [Medline: 31037858]

10. Cook RL, Sereika SM, Hunt SC, Woodward WC, Erlen JA, Conigliaro J. Problem drinking and medication adherence among persons with HIV infection. J Gen Intern Med 2001 Feb;16(2):83-88. [doi: 10.1111/j.1525-1497.2001.00122.x] [Medline: 11251758 ]

11. Sankar A, Wunderlich T, Neufeld S, Luborsky M. Sero-positive African Americans' beliefs about alcohol and their impact on anti-retroviral adherence. AIDS Behav 2007 Mar;11(2):195-203 [FREE Full text] [doi: 10.1007/s10461-006-9144-0] [Medline: 16799842]

12. Chander G, Lau B, Moore RD. Hazardous alcohol use: a risk factor for non-adherence and lack of suppression in HIV infection. J Acquir Immune Defic Syndr 2006 Dec 01;43(4):411-417 [FREE Full text] [doi:

10.1097/01.qai.0000243121.44659.a4] [Medline: 17099312]

13. Samet JH, Cheng DM, Libman H, Nunes DP, Alperen JK, Saitz R. Alcohol consumption and HIV disease progression. J Acquir Immune Defic Syndr 2007 Oct 01;46(2):194-199 [EREE Full text] [doi: 10.1097/QAI.0b013e318142aabb] [Medline: 17667330]

14. Braithwaite R, Conigliaro J, McGinnis K, Maisto S, Bryant K, Justice A. Adjusting alcohol quantity for mean consumption and intoxication threshold improves prediction of nonadherence in HIV patients and HIV-negative controls. Alcohol Clin Exp Res 2008 Sep;32(9):1645-1651 [FREE Full text] [doi: 10.1111/j.1530-0277.2008.00732.x] [Medline: 18616666]

15. Conigliaro J, Justice AC, Gordon AJ, Bryant K, VACS AlcoholBehavior Change Research Group. Role of alcohol in determining human immunodeficiency virus (HIV)-relevant outcomes: A conceptual model to guide the implementation of evidence-based interventions into practice. Med Care 2006 Aug;44(8 Suppl 2):S1-S6. [doi:

$\underline{\text { 10.1097/01.mlr.0000223659.36369.cf] [Medline: } 16849963 \text { ] }}$

16. Bryant KJ. Expanding research on the role of alcohol consumption and related risks in the prevention and treatment of HIV/AIDS. Subst Use Misuse 2006;41(10-12):1465-1507. [doi: 10.1080/10826080600846250] [Medline: 17002990] 
17. Galvan FH, Bing EG, Fleishman JA, London AS, Caetano R, Burnam MA, et al. The prevalence of alcohol consumption and heavy drinking among people with HIV in the United States: results from the HIV Cost and Services Utilization Study. J Stud Alcohol 2002 Mar;63(2):179-186. [doi: 10.15288/jsa.2002.63.179] [Medline: 12033694]

18. Samet JH, Horton NJ, Meli S, Freedberg KA, Palepu A. Alcohol consumption and antiretroviral adherence among HIV-infected persons with alcohol problems. Alcohol Clin Exp Res 2004 Apr;28(4):572-577. [doi:

10.1097/01.alc.0000122103.74491.78] [Medline: 15100608]

19. Santos G, Jin H, Raymond HF. Pervasive Heavy Alcohol Use and Correlates of Increasing Levels of Binge Drinking among Men Who Have Sex with Men, San Francisco, 2011. J Urban Health 2015 Aug;92(4):687-700 [FREE Full text] [doi: 10.1007/s11524-015-9958-z] [Medline: 25895622]

20. Hess KL, Chavez PR, Kanny D, DiNenno E, Lansky A, Paz-Bailey G, NHBS Study Group. Binge drinking and risky sexual behavior among HIV-negative and unknown HIV status men who have sex with men, 20 US cities. Drug Alcohol Depend 2015 Feb 01;147:46-52 [FREE Full text] [doi: 10.1016/j.drugalcdep.2014.12.013] [Medline: 25555622]

21. Institute of Medicine. The Health of Lesbian, Gay, Bisexual, and Transgender People: Building a Foundation for Better Understanding. Washington DC: The National Academies Press; 2011.

22. James S, Herman J, Rankin S, Keisling M, Mottet L, Anafi M. The Report of the 2015 US Transgender Survey. National Center for Transgender Equality; Washington DC. URL: https://www.transequality.org/sites/default/files/docs/ USTS-Full-Report-FINAL.PDF [accessed 2020-06-01]

23. Wardell J, Shuper P, Rourke S, Hendershot C. Stigma, Coping, and Alcohol Use Severity Among People Living With HIV: A Prospective Analysis of Bidirectional and Mediated Associations. Ann Behav Med 2018 Aug 16;52(9):762-772 [FREE Full text] [doi: $10.1093 / \mathrm{abm} / \mathrm{kax} 050]$ [Medline: $\underline{\text { 30124756] }}$

24. Batchelder AW, Safren S, Mitchell AD, Ivardic I, O'Cleirigh C. Mental health in 2020 for men who have sex with men in the United States. Sex Health 2017 Feb;14(1):59-71 [FREE Full text] [doi: 10.1071/SH16083] [Medline: 28055823]

25. Rowe C, Santos G, McFarland W, Wilson EC. Prevalence and correlates of substance use among trans female youth ages 16-24 years in the San Francisco Bay Area. Drug Alcohol Depend 2015 Feb 01;147:160-166 [FREE Full text] [doi: 10.1016/j.drugalcdep.2014.11.023] [Medline: 25548025]

26. Gonzalez A, Barinas J, O'Cleirigh C. Substance use: impact on adherence and HIV medical treatment. Curr HIV/AIDS Rep 2011 Dec;8(4):223-234. [doi: 10.1007/s11904-011-0093-5] [Medline: 21858414]

27. Spire B, Duran S, Souville M, Leport C, Raffi F, Moatti J, APROCO cohort study group. Adherence to highly active antiretroviral therapies (HAART) in HIV-infected patients: from a predictive to a dynamic approach. Soc Sci Med 2002 May;54(10):1481-1496. [doi: 10.1016/s0277-9536(01)00125-3] [Medline: 12061483]

28. Turner CM, Coffin P, Santos D, Huffaker S, Matheson T, Euren J, et al. Race/ethnicity, education, and age are associated with engagement in ecological momentary assessment text messaging among substance-using MSM in San Francisco. J Subst Abuse Treat 2017 Apr;75:43-48 [FREE Full text] [doi: 10.1016/j.jsat.2017.01.007] [Medline: 28237053]

29. Yang C, Linas B, Kirk G, Bollinger R, Chang L, Chander G, et al. Feasibility and Acceptability of Smartphone-Based Ecological Momentary Assessment of Alcohol Use Among African American Men Who Have Sex With Men in Baltimore. JMIR Mhealth Uhealth 2015 Jun 17;3(2):e67 [FREE Full text] [doi: 10.2196/mhealth.4344] [Medline: 26085078]

30. Rendina HJ, Ventuneac A, Mustanski B, Grov C, Parsons JT. Prospective Measurement of Daily Health Behaviors: Modeling Temporal Patterns in Missing Data, Sexual Behavior, and Substance Use in an Online Daily Diary Study of Gay and Bisexual Men. AIDS Behav 2016 Aug;20(8):1730-1743 [FREE Full text] [doi: 10.1007/s10461-016-1359-0] [Medline: 26992392]

31. Westergaard RP, Genz A, Panico K, Surkan PJ, Keruly J, Hutton HE, et al. Acceptability of a mobile health intervention to enhance HIV care coordination for patients with substance use disorders. Addict Sci Clin Pract 2017 Apr 26;12(1):11 [FREE Full text] [doi: 10.1186/s13722-017-0076-y] [Medline: 28441962]

32. Hensel DJ, Fortenberry JD, Harezlak J, Craig D. The feasibility of cell phone based electronic diaries for STI/HIV research. BMC Med Res Methodol 2012 Jun 12;12:75 [FREE Full text] [doi: 10.1186/1471-2288-12-75] [Medline: 22691189]

33. Moore RC, Kaufmann CN, Rooney AS, Moore DJ, Eyler LT, Granholm E, et al. Feasibility and Acceptability of Ecological Momentary Assessment of Daily Functioning Among Older Adults with HIV. Am J Geriatr Psychiatry 2017 Aug;25(8):829-840 [FREE Full text] [doi: 10.1016/j.jagp.2016.11.019] [Medline: 28065496]

34. Cherenack EM, Wilson PA, Kreuzman AM, Price GN, Adolescent Medicine Trials Network for HIV/AIDS Interventions. The Feasibility and Acceptability of Using Technology-Based Daily Diaries with HIV-Infected Young Men Who have Sex with Men: A Comparison of Internet and Voice Modalities. AIDS Behav 2016 Aug;20(8):1744-1753 [FREE Full text] [doi: 10.1007/s10461-016-1302-4] [Medline: 26837629]

35. Kingdon MJ, Storholm ED, Halkitis PN, Jones DC, Moeller RW, Siconolfi D, et al. Targeting HIV prevention messaging to a new generation of gay, bisexual, and other young men who have sex with men. J Health Commun 2013;18(3):325-342. [doi: 10.1080/10810730.2012.727953] [Medline: 23320963]

36. Kubicek K, Carpineto J, McDavitt B, Weiss G, Iverson EF, Au C, et al. Integrating professional and folk models of HIV risk: YMSM's perceptions of high-risk sex. AIDS Educ Prev 2008 Jun;20(3):220-238 [FREE Full text] [doi:

10.1521/aeap.2008.20.3.220] [Medline: 18558819] 
37. Kubicek K, Carpineto J, McDavitt B, Weiss G, Kipke MD. Use and perceptions of the internet for sexual information and partners: a study of young men who have sex with men. Arch Sex Behav 2011 Aug;40(4):803-816 [FREE Full text] [doi: 10.1007/s10508-010-9666-4] [Medline: 20809373]

38. Turner CM, Arayasirikul S, Trujillo D, Lê V, Wilson EC. Social Inequity and Structural Barriers to Completion of Ecological Momentary Assessments for Young Men Who Have Sex With Men and Trans Women Living With HIV in San Francisco. JMIR Mhealth Uhealth 2019 May 08;7(5):e13241 [FREE Full text] [doi: 10.2196/13241] [Medline: $\underline{31066714}$ ]

39. Parsons JT, Rosof E, Mustanski B. The temporal relationship between alcohol consumption and HIV-medication adherence: a multilevel model of direct and moderating effects. Health Psychol 2008 Sep;27(5):628-637 [FREE Full text] [doi: 10.1037/a0012664] [Medline: 18823189$]$

40. Barai N, Monroe A, Lesko C, Lau B, Hutton H, Yang C, et al. The Association Between Changes in Alcohol Use and Changes in Antiretroviral Therapy Adherence and Viral Suppression Among Women Living with HIV. AIDS Behav 2017 Jul;21(7):1836-1845 [FREE Full text] [doi: 10.1007/s10461-016-1580-x] [Medline: 27752873]

41. Arayasirikul S, Trujillo D, Turner CM, Le V, Wilson EC. Implementing a Digital HIV Care Navigation Intervention (Health eNav): Protocol for a Feasibility Study. JMIR Res Protoc 2019 Nov 08;8(11):e16406 [FREE Full text] [doi: 10.2196/16406] [Medline: $\underline{31702561]}$

42. mSurvey. URL: https://msurvey.co/ [accessed 2019-04-18]

43. Hendershot CS, Stoner SA, Pantalone DW, Simoni JM. Alcohol use and antiretroviral adherence: review and meta-analysis. J Acquir Immune Defic Syndr 2009 Oct 01;52(2):180-202 [FREE Full text] [doi: 10.1097/QAI.0b013e3181b18b6e] [Medline: 19668086]

44. Ji L, Chow S, Schermerhorn AC, Jacobson NC, Cummings EM. Handling Missing Data in the Modeling of Intensive Longitudinal Data. Struct Equ Modeling 2018;25(5):715-736 [FREE Full text] [doi: 10.1080/10705511.2017.1417046] [Medline: 31303745]

45. Young R, Johnson DR. Handling Missing Values in Longitudinal Panel Data With Multiple Imputation. J Marriage Fam 2015 Feb;77(1):277-294 [FREE Full text] [doi: 10.1111/jomf.12144] [Medline: 26113748]

\section{Abbreviations}

ART: antiretroviral therapy

CASI: computer-administered self-interviewing

CDC: Centers for Disease Control and Prevention

EMA: ecological momentary assessment

GED: General Educational Development

MSM: men who have sex with men

TW: trans women

UNAIDS: Joint United Nations Programme on HIV/AIDS

Edited by G Eysenbach; submitted 21.07.20; peer-reviewed by L Chang, C Latkin; comments to author 11.08.20; revised version
received 16.09.20; accepted 16.09.20; published 15.10.20
Please cite as:
Turner CM, Trujillo D, Le V, Wilson EC, Arayasirikul S
Event-Level Association Between Daily Alcohol Use and Same-Day Nonadherence to Antiretroviral Therapy Among Young Men Who
Have Sex With Men and Trans Women Living With HIV: Intensive Longitudinal Study
JMIR Mhealth Uhealth 2020;8(10):e22733
URL: $\underline{\text { http://mhealth.jmir.org/2020/10/e22733/ }}$
doi: $10.2196 / 22733$
PMID: $\underline{33055070}$

(C) Caitlin Marie Turner, Dillon Trujillo, Victory Le, Erin C Wilson, Sean Arayasirikul. Originally published in JMIR mHealth and uHealth (http://mhealth.jmir.org), 15.10.2020. This is an open-access article distributed under the terms of the Creative Commons Attribution License (https://creativecommons.org/licenses/by/4.0/), which permits unrestricted use, distribution, and reproduction in any medium, provided the original work, first published in JMIR mHealth and uHealth, is properly cited. The complete bibliographic information, a link to the original publication on http://mhealth.jmir.org/, as well as this copyright and license information must be included. 